\title{
Expression of Nesfatin-1/NUCB2 in Fetal, Neonatal and Adult Mice
}

\author{
Yiwa Chung, Eunhye Jung ${ }^{1}$, Heejung Kim${ }^{1}$, Jinhee $\mathrm{Kim}^{2}$ and ${ }^{\dagger}$ Hyunwon Yang ${ }^{1}$ \\ ${ }^{1}$ Department of Bioenvironmental Technology, College of Natural Sciences, Seoul Women's University, \\ Seoul 139-774, Republic of Korea \\ ${ }^{2}$ Fertility Center, CHA Gangnam Medical Center, CHA University, Seoul 135-913, Republic of Korea
}

\begin{abstract}
Nesfatin-1/NUCB2, which is associated with the control of appetite and energy metabolism, was reported for the first time to be expressed in the hypothalamus. However, recent studies have shown that nesfatin-1/NUCB2 was expressed not only in the hypothalamus, but also in various tissues including digestive and reproductive organs. We also demonstrated that nesfatin-1/NUCB2 was expressed in the reproductive organs, pituitary gland, heart, lung, and gastrointestinal tract of the adult mouse. However, little is known about nesfatin-1/NUCB2 expression in fetal and neonatal mice. Therefore, we examined here the distribution of nesfatin-1/NUCB2 in various organs of fetal and neonatal mice and compared them with the distribution in adult mice. As a result of immunohistochemical staining, nesfatin-1/NUCB2 protein was expressed relatively higher in the lung, kidney, heart, and liver compared to other organs in the fetus. Western blot results also showed that nesfatin-1/NUCB2 protein was detected in the lung, kidney, heart, and stomach. Next, we compared the expression levels of nesfatin-1/NUCB2 mRNA in the fetus and neonate with the expression levels in both male and female adult mice. The expression levels in heart, lung, stomach, and kidney were higher compared with other organs in fetal and neonatal mice and in both male and female adult mice. Interestingly, the expression of nesfatin-1/NUCB2 mRNA in the kidney was dramatically increased in male and female adult mice compared to fetal and neonatal mice. These results indicate that nesfatin-1/NUCB2 may regulate the development and physiological function of mouse organs. In the future, we need more study on the function of nesfatin-1/NUCB2, which is highly expressed in the heart, lung, and kidney during mouse development.
\end{abstract}

Key words : Fetus, Mouse development, Neonate, Nesfatin-1/NUCB2

\section{INTRODUCTION}

Nucleobindin precursor protein, which was identified for the first time in the human and mouse cell lines, is known to have two isotypes, nucleobindin 1 (NUCB1) and nucleobindin 2 (NUCB2) (Barnikol-Watanabe et al., 1994; Kanai \& Tanuma, 1992; Miura et al., 1992). This precursor protein contains multiple functional domains including a signal peptide on the N-terminal side, a leucine/ isoleucine rich region, a DNA binding domain and a putative nuclear targeting signal, while the second half contains two $\mathrm{Ca}^{2+}$-EF-hand motifs and a leucine zipper motif in the C-terminal region (Barnikol-Watanabe et al., 1994). However, NUCB2 only functions physiologically in humans and rodents (Miura et al., 1992). NUCB2 produces nesfatin-1 (residues 1-82), nesfatin-2 (residues 85-163), and nesfatin-3 (residues 166-396) by the enzyme pro-hormone convertase (PC)-1/3 after putative post-translational processing. Until now, a physiological activity has only been demonstrated for nesfatin-1 (Oh-I et al., 2006; Stengel et

\footnotetext{
Manuscript received 30 November 2013, Received in revised form 19 December 2013, Accepted 22 December 2013

† Corresponding Author : Hyunwon Yang, Department of Bioenvironmental Technology, Seoul Women's University, 621 Hwarangro, Nowon-gu, Seoul 139-774, Republic of Korea. Tel. : +82-2-970-5662, Fax : +82-2-970-5974, E-mail : hwyang@swu.ac.kr

This is an Open Access article distributed under the terms of the Creative Commons Attribution Non-Commercial License(http://creativecommons. org/licenses/by-nc/3.0) which permits unrestricted non-commercial use, distribution, and reproduction in any medium, provided the original work is properly cited.
} 
Y Chung, E Jung, H Kim, J Kim, H Yang

al., 2012).

Nesfatin-1/NUCB2 is initially known to be expressed in the hypothalamic nuclei for appetite control and to exist in the cerebrospinal fluid and brain stem in rats (Brailoiu et al., 2007; Foo et al., 2008; Fort et al., 2008; Kohno et al., 2008). Recent study demonstrated that nesfatin- $1 /$ NUCB2 was identified in the rat gastric organs (Gonzalez et al., 2009; Stengel et al., 2009a). A large amount of the nesfatin-1 expression was detected in gastric endocrine cells and the duodenal Brunner's glands of the rodents (Zhang et al., 2010). X/A-like cells secreted ghrelin, which stimulates the appetite in the gastric mucosal layer, was also demonstrated to express nesfatin-1/NUCB2 (Stengel et al., 2009b). Nesfatin-1/NUCB2 immunoreactive cells are also co-localized with insulin in pancreatic $\beta$-cells of mouse and rat (Gonzalez et al., 2009), suggesting a potential role for nesfatin-1 in pancreatic islet and glucose homeostasis (Foo et al., 2010). Recently, nesfatin-1 was detected in the fat of human and rodent showing that it was expressed more in the subcutaneous than in the visceral fat (Ramanjaneya et al., 2010). A few studies have demonstrated that nesfatin- 1 proteins are expressed in the heart, as a cardiac peptide (Angelone et al., 2012; Mimee et al., 2012; Yosten \& Samson, 2009). In addition, several recent studies showed the expression of nesfatin-1 in the male reproductive system of human and rodent (García-Galiano et al., 2010; García-Galiano et al., 2012; Kim et al., 2011a). Furthermore, our previous papers have shown that nesfatin-1 and its binding sites are expressed in the female mouse reproductive organs (Kim et al., 2010; Kim et al., 2011b).

Until now, there have been many reports that nesfatin-1/ NUCB2 is expressed in various organs in adult rodent and human. However, little is known about nesfatin-1/ NUCB2 expression in fetus and neonate. Therefore, we examined here the expression of nesfatin-1/NUCB2 in various organs of fetal and neonatal mice and compared them with the expression in adult mouse. We first investigated whether nesfatin-1/NUCB2 are expressed in fetal and neonatal mice by immunohistochemical staining and
Western blot. Next, the expression levels of NUCB2 mRNA in fetal and neonatal mice were measured by qRT-PCR and compared to expression levels in male and female adult mice.

\section{MATERIALS AND METHODS}

\section{Animal}

Pregnant ICR mice were purchased from Samtako Bio Korea (South Korea) and housed in groups of five per cage under controlled illumination (12:12 h light/dark cycle, lights on/off: $6 \mathrm{~h} / 18 \mathrm{~h})$ and temperature $\left(22 \pm 2^{\circ} \mathrm{C}\right)$. Animals were fed a standard rodent diet and tap water ad libitum. Mice were euthanized by $\mathrm{CO}_{2}$ anesthesia followed by cervical dislocation. The fetal and neonatal mice were collected on day 15.5 postcoitus and on day 3 after birth, respectively. Animal care and experimental procedures were approved by the Institutional Animal care and the use committee at the Seoul Women's University in accordance with guidelines established by the Korea Food and Drug Administration.

\section{RNA extraction and cDNA synthesis}

Mice were euthanized by $\mathrm{CO}_{2}$ anesthesia followed by cervical dislocation. Each organ was quickly removed and homogenized with $300 \mu$ ice cold RNA isoplus (TaKaRa Bio, Shiga, Japan). After chloroform extraction and isopropyl alcohol precipitation, RNA was dissolved in $20 \mu \mathrm{l}$ RNase-free DEPC (TaKaRa Bio, Shiga, Japan) solution. The RNA concentrations were measured with the Nano-drop (Thermo Fisher Scientific Inc., Waltham, MA). First strand cDNA synthesis was performed using $2 \mu \mathrm{g}$ RNA, 10 pmol oligo dT and RNase-free DEPC solution at $70^{\circ} \mathrm{C}$ for $5 \mathrm{~min}$, followed by double-strand synthesis in 5X RT buffer (Invitrogen, Carlsbad, CA) with 8 mM dNTP (BIO BASIC INC., Ontario, Canada), 200

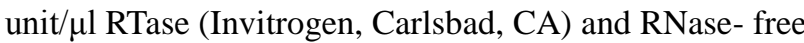
DEPC solution at $37^{\circ} \mathrm{C}$ for $60 \mathrm{~min}$ and at $72^{\circ} \mathrm{C}$ for $15 \mathrm{~min}$.

\section{3. qRT-PCR}


qRT-PCR was performed in a total volume of $20 \mu \mathrm{l}$ buffer solution containing $2 \mu \mathrm{l}$ of template cDNA, $10 \mu \mathrm{l}$ of SYBR Green (Roche, Manheim, Germany), and 10 pmol of each primer. Primer pairs were as follows: NUCB2 forward 5'-AAAACCTTGGCCTGTCTGAA-3'; reverse 5'-CATCGATAGGAACAGCTTCCA-3' and GAPDH forward 5'-TTGATGGCAACAATCTCCAC-3'; reverse 5'-CGTCCCGTAGACAAAATGGT-3' (BIONICS, Korea).

The optimal temperature cycling protocol was determined to be $95^{\circ} \mathrm{C}$ for 5 min followed by 45 reaction cycles at $95^{\circ} \mathrm{C}$ for $10 \mathrm{~s}, 60^{\circ} \mathrm{C}$ for $10 \mathrm{~s}$ and $72^{\circ} \mathrm{C}$ for $10 \mathrm{~s}$ using the LightCycler ${ }^{\circledR} 480$ Real-time PCR System (Roche, Manheim, Germany).

\section{Western blot analysis}

All tissues were homogenized with $300 \mu 1$ ice cold EDTA homogenization buffer (0.606 g Tris-Base, 0.876 g NaCl, 0.036 g EDTA, $100 \mu 1$ Tween 20, 100 mM PMSF in $100 \mathrm{ml} \mathrm{DW}$ ). Protein fractions were obtained by centrifugation at $14,000 \mathrm{rpm}$ for $20 \mathrm{~min}$ at $4{ }^{\circ} \mathrm{C}$. Final protein concentrations were determined using a BCA protein assay according to the SpectraMax M3 Multi-Mode Microplate Reader (Molecular Devices, Sunnyvale, CA). Protein samples $(20 \mu \mathrm{g})$ were mixed with EDTA homogenization buffer, $1 \mu 1$ 5\% mercaptoethanol, and $4 \mu 1$ $5 \mathrm{X}$ SDS sample loading buffer, and then boiled at $95^{\circ} \mathrm{C}$ for $5 \mathrm{~min}$. The samples were loaded on a 12\% SDS-PAGE gel and run in $1 \mathrm{X}$ Tris-Glycine SDS Running buffer (KOMABIOTECH, Korea). After gel running, proteins were transferred by electrophoresis to PVDF membrane (Amersham; GE Healthcare, Buckinghamshire, England) for $24 \mathrm{~h}$ at $4^{\circ} \mathrm{C}$. The membrane was stained in Ponceau-S and washed in distilled water, and then incubated in 3\% Casein/PBS Blocking Solution (Komabiotech, Korea) for $2 \mathrm{~h}$ at room temperature. The membrane was incubated with rabbit anti-rat nesfatin-1 polyclonal antibody (Phoenix Pharmaceuticals, INC., Burlingame, CA) and anti-mouse $\beta$-actin antibody (Santa Cruz Biotechnology, Inc., Paso Robles, CA) for $1 \mathrm{~h}$ at room temperature. The membrane was washed three times with washing buffer and incubated with goat anti-rabbit IgG-HRP (Santa Cruz Biotechnology, Inc., Paso Robles, CA) and donkey anti-mouse IgG-HRP (Santa Cruz Biotechnology, Inc., Paso Robles, CA) for $1 \mathrm{~h}$, respectively. After washing three times, the membrane was detected by ECL Plus Western Blotting Detection Reagents (Amersham; GE Healthcare, Buckinghamshire, England). The relative protein levels were analyzed by Scion Image (National Institutes of Health, Bethesda, MD).

\section{Immunohistochemistry staining}

The tissues were fixed in $4 \%$ paraformaldehyde buffer saline for $2 \mathrm{~h}$ or immersed in $20 \%$ sucrose solution before freezing. The tissues were rinsed in ethanol series to remove fixative residues, embedded in paraffin block. The tissues blocks were cut $10 \mu \mathrm{m}$ sections using a microtome, deparaffinized, and rehydrated with graded xylene-alcohol series, and then washed with PBS before immunostaining. The sections were incubated with rabbit anti-rat nesfatin-1 polyclonal antibody (Phoenix Pharmaceuticals, INC., Burlingame, CA) at $4^{\circ} \mathrm{C}$ for overnight followed by incubation with Alexa fluor 594 conjugated goat anti-rabbit IgG (Jackson immuno research laboratory, West grove, PA). The sections were counter stained with DAPI (4',6-diamidino-2-phenylindole; Sigma, St. Louis, MO) for 10 min and mounted on the slides with mounting medium (Vector laboratories, INC., Burlingame, CA), and then observed under fluorescence microscopy (Axioskop2, Carl Zeiss, Germany).

\section{RESULTS}

1. Expression of nesfatin-1/NUCB2 in fetal mouse We first investigated nesfatin-1/NUCB2 expression in various organs of the fetal and neonatal mice by immunohistochemical staining and Western blot to figure out whether nesfatin-1/NUCB2 is involved in the development of mice. Nesfatin-1/NUCB2 immunoactive cells were detected in various tissues in fetus. Especially, nesfatin-1/ NUCB2 protein was highly expressed in spinal cord, lung, liver, gonad, and kidney (Fig. 1). Western bolt 
A.

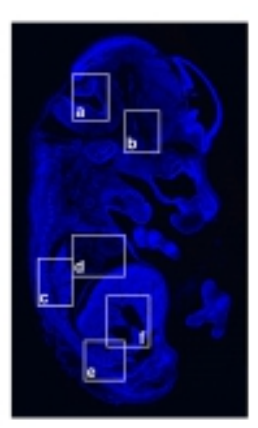

B.

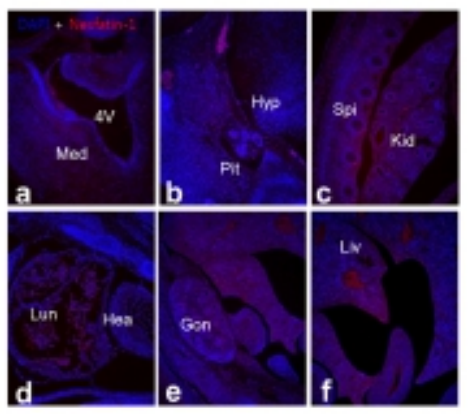

Fig. 1. Localization of nesfatin-1/NUCB2 protein in fetal mouse.

(A) Fetal mouse section was stained with nesfatin-1 antibody to localize nesfatin-1/NUCB2 protein and observed under fluorescence microscopy. (B) Nesfatin-1/NUCB2 immunoactive cells were detected in various tissues in fetus. Nesfatin-1/NUCB2 protein was highly expressed in spinal cord, lung, liver, gonad, and kidney. $4 \mathrm{~V}, 4^{\text {th }}$ ventricle; Med, Medulla; Pit, Pituitary; Spi, Spinal cord; Kid, Kidney; Lun, Lung; Hea, Heart; Gon, Gonad; Liv, Liver. Original magnification (A) $25 \times$, (B) $100 \times$.
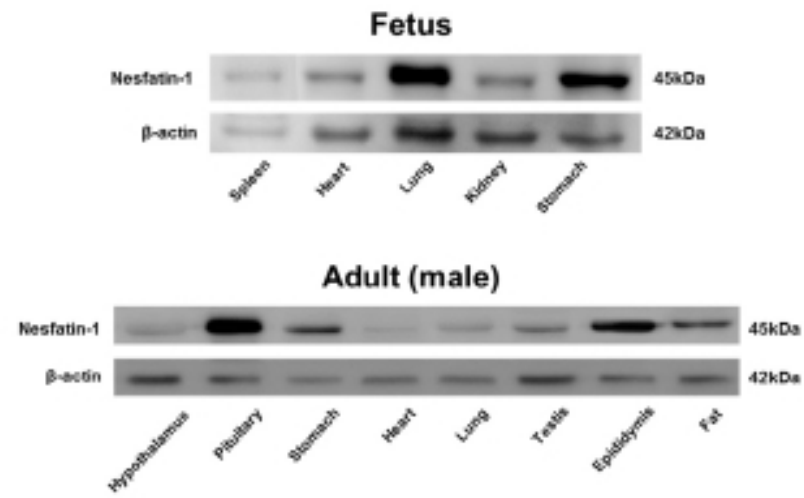

Adult (Female)

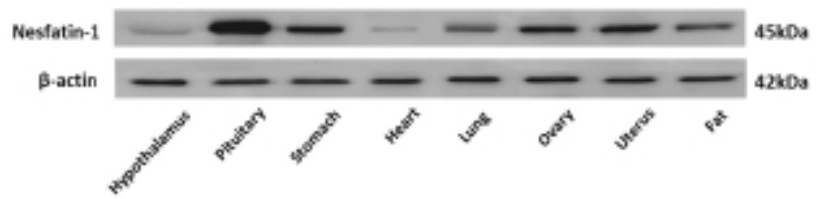

Fig. 2. Detection of nesfatin-1/NUCB2 protein in various tissues of fetal and adult mice. Nesfatin-1/NUCB2 protein in various tissues of fetal and adult mice was detected by western blot, showing a high expression in lung and stomach. The expression levels of nesfatin-1/NUCB2 mRNA in lung and stomach were higher in the fetus than in both male and female adult mice.

results showed that nesfatin-1/NUCB2 protein was detected in various organs in fetus similar to immunohistochemistry result, showing high expression in lung and stomach
(Fig. 2). Interestingly, the expression levels of nesfatin-1/ NUCB2 mRNA in lung and stomach were higher in the fetus than in both male and female adult mice (Fig. 2).

\section{Comparison of nesfatin-1/NUCB2 mRNA expression} between fetal, neonatal, and adult mice

We measured the expression levels of NUCB2 mRNA in fetal and neonatal mice by qRT-PCR and compared them with the expression levels in male and female adult mice. The expression levels of nesfatin-1/NUCB2 mRNA were relatively higher in heart, lung, stomach, and kidney compared to other organs (Fig. 3). In adult mouse, the expression levels were also higher in heart, lung, stomach, and kidney similar to them in fetus and neonate. However, kidney showed extremely high expression of nesfatin-1/NUCB2 mRNA in both male and female adult mice compared to fetus and neonate. Interestingly, the expression was reduced in the stomach of female mouse compared to the fetal and neonatal mice (Fig. 3).
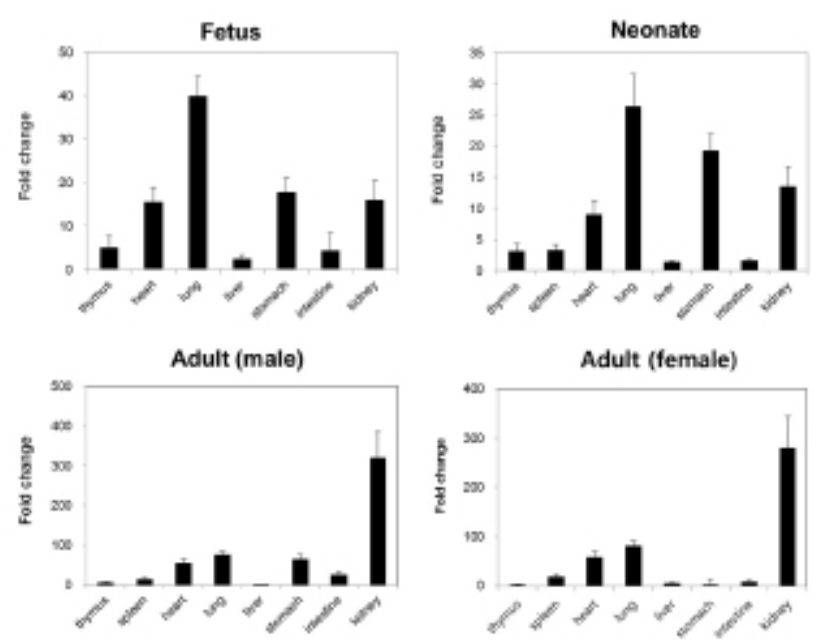

Fig. 3. Nesfatin-1/NUCB2 mRNA expression in fetal, neonatal, and adult mouse. The expression levels of nesfatin-1/ NUCB2 mRNA in fetal and neonatal mice were measured by qRT-PCR and compared with male and female adult mice. The expression levels of nesfatin-1/NUCB2 mRNA were relatively higher in heart, lung, stomach, and kidney compared to other organs in fetus. In adult mouse, the expression levels were also higher in heart, lung, stomach, and kidney similar to fetus and neonate. All data are represented as mean \pm SEM $(n=3)$. 


\section{DISCUSSION}

Since nesfatin-1/NUCB2 involved in the control of appetite and energy metabolism was discovered for the first time in the hypothalamus (Oh-I et al., 2006), many studies have shown that nesfatin-1/NUCB2 is expressed not only in the hypothalamus, but also in various tissues such as stomach, pancreas, and adipose tissues of humans and rodents (Garcia-Galiano et al., 2010; Stengel et al., 2009b). All studies on nesfatin-1/ NUCB2 expression and function have been focused on adult so far, but there exists no report on fetus and neonate. Therefore, we examined the expression of nesfatin-1/ NUCB2 in various organs of fetal and neonatal mice and compared them with the expression in adult mouse. In the present study, we demonstrated for the first time that nesfatin-1/NUCB2 protein and mRNA are expressed in the fetal and neonatal mice.

As a result of immunohistochemical staining, nesfatin-1/ NUCB2 protein was expressed relatively higher in the spinal cord, lung, liver, gonad, and kidney compared to other organs in fetus. There are currently no reports that nesfatin-1/NUCB2 protein and mRNA are expressed in the spinal cord, lung, liver, gonad, and kidney of fetal or even adult mice. Only our previous papers have shown that nesfatin-1/NUCB2 protein and mRNA are expressed in the lung, liver, and gonad of adult mouse (Kim et al., 2010; Kim et al., 2011b). Although there are currently no references regarding to the expression of nesfatin-1/ NUCB2 in organs of fetal mouse, the present results suggest that nesfatin-1/NUCB2 may be associated with each organ formation during mouse fetus development.

Western blot results also showed that nesfatin-1/NUCB2 protein was detected in various organs in fetal mouse, showing a high expression in lung and stomach. Moreover, the expression levels of nesfatin-1/NUCB2 protein in lung and stomach in the fetus were higher than those of both male and female adult mice. There have been many reports that nesfatin-1/NUCB2 is expressed in gastric system including stomach. Large amounts of the nesfatin-1/NUCB2 expression were detected in the digestive organs as well as in the hypothalamus and brain stem. In particular, nesfatin-1/NUCB2 is markedly expressed in the pancreas, stomach, and duodenum of rodent and canine (Gonkowski et al., 2012; Iwasaki et al., 2012; Mohan \& Unniappan, 2012; Osaki et al., 2012; Stengel et al., 2009c; Stengel \& Taché, 2012; Zhang et al., 2010). In the stomach, nesfatin-1/NUCB2 immunosignals are mainly localized in mucosal endocrine X/A-like cells within a distinct sub-population of vesicles different from those containing the orexigenic hormone ghrelin, suggesting differential regulation and release of ghrelin and nesfatin-1/NUCB2 (Li et al., 2012; Stengel et al., 2009c; Stengel \& Taché, 2010). Although we have knowledge of the expression and function of nesfatin-1/NUCB2 in the stomach of adult mouse, its roles in fetus are still unknown.

Next, we analyzed the expression levels of nesfatin-1/ NUCB2 mRNA in fetus and neonate by qRT-PCR. The expression levels in heart, lung, stomach, and kidney were higher compared with other organs in fetal and neonatal mice similar to Western blot results. A few studies have demonstrated that nesfatin-1 proteins are expressed in the heart of adult mouse and human, as a cardiac peptide (Angelone et al., 2012; Mimee et al., 2012; Yosten \& Samson, 2009). Nesfatin-1 is known to protect the heart against ischemia/reperfusion injury through activation of multiple prosurvival kinases such as PKC and ERK1/2 (Mimee et al., 2012). However, there are currently no reports that nesfatin-1/NUCB2 protein and mRNA are expressed in fetal and neonatal heart. Meanwhile, nesfatin-1/NUCB2 mRNA was expressed the highest in fetal and neonatal lung compared to other organs. In addition, the expression of nesfatin-1/NUCB2 mRNA in the kidney was dramatically increased in male and female adult mice compared to in fetal and neonatal mice. Unfortunately, little is known about the expression and function in the lung and kidney of fetal and even adult mice. We need more study of why nesfatin-1/ NUCB2 protein and mRNA show high expression levels in the lung of fetus and neonate and in the kidney of adult mouse. 
These results indicate that nesfatin-1/NUCB2 may regulate the development and physiological function in mouse organs. In the future, we need more study on the function of nesfatin-1/NUCB2 which is highly expressed in the heart, lung, and kidney during mouse development.

\section{ACKNOWLEDGEMENTS}

This work was supported by a special research grant from Seoul Women's University (2013).

\section{REFERENCES}

Angelone T, Filice E, Pasqua T, Amodio N, Galluccio M, Montesanti G, Quintieri AM, Cerra MC (2012) Nesfatin-1 as a novel cardiac peptide: identification, functional characterization, and protection against ischemia/reperfusion injury. Cell Mol Life Sci 70: 495-509.

Barnikol-Watanabe S, Gross NA, Gotz H, Henkel T, Karabinos A, Kratzin H, Barnikol HU, Hilschmann N (1994) Human protein NEFA, a novel DNA binding/ EF-hand/leucine zipper protein. Molecular cloning and sequence analysis of the cDNA, isolation and characterization of the protein. Biol Chem Hoppe Seyler 375:497-512.

Brailoiu GC, Dun SL, Brailoiu E, Inan S, Yang J, Chang JK, Dun NJ (2007) Nesfatin-1: distribution and interaction with a $\mathrm{G}$ protein coupled receptor in the rat brain. Endocrinology 148:5088-5094.

Foo KS, Brauner H, Ostenson CG, Broberger C (2010) Nucleobindin-2/nesfatin in the endocrine pancreas: distribution and relationship to glycaemic state. J Endocrinol 204:255-263.

García-Galiano D, Navarro VM, Gaytan F, Tena-Sempere M (2010) Expanding roles of NUCB2/nesfatin-1 in neuroendocrine regulation. J Mol Endocrinol 45:281-290.

García-Galiano D, Pineda R, Ilhan T, Castellano JM, Ruiz-Pino F, Sánchez-Garrido MA, Vazquez MJ, SangiaoAlvarellos S, Romero-Ruiz A, Pinilla L, Diéguez C,
Gaytán F, Tena-Sempere M (2012) Cellular distribution, regulated expression, and functional role of the anorexigenic peptide, NUCB2/nesfatin-1, in the testis. Endocrinology 153:1959-1971.

Gonkowski A, Rychlik A, Nowicki M, Nieradka R, Bulc M, Całka J (2012) A population of nesfatin 1-like immunoreactive (LI) cells in the mucosal layer of the canine digestive tract. Res Vet Sci 93:1119-1121.

Gonzalez R, Tiwari A, Unniappan S (2009) Pancreatic beta cells colocalize insulin and pronesfatin immunoreactivity in rodents. Biochem Biophys Res Commun 381:643-648.

Iwasaki Y, Yada T (2012) Vagal afferents sense mealassociated gastrointestinal and pancreatic hormones: Mechanism and physiological role. Neuropeptides 46: 291-297.

Kanai Y, Tanuma S (1992) Purification of a novel B cell growth and differentiation factor associated with lupus syndrome. Immunol Lett 32:43-48.

Kim JH, Kim HS, Kim SM, Yang HJ, Cho HH, Hwang SP, Moon CI, Yang HW (2011a) Expression of nesfatin-1/NUCB2 and its binding site in mouse testis and epididymis. Dev Reprod 15:249-256.

Kim JH, Lee KR, Kim HK, No SH, Yoo HM, Moon CI, Yang HW (2011b) 17beta-estradiol regulates the expression of nesfatin-1/Nucb2 in mouse uterus. Dev Reprod 15:349-357.

Kim JH, Youn MR, Bang SY, Sim JY, Kang HR, Yang HW (2010) Expression of nesfatin-1/NUCB2 and its binding site in mouse ovary. Dev Reprod 14:287-295.

Li Z, Xu G, Li Y, Zhao J, Mulholland MW, Zhang W (2012) mTOR-dependent modulation of gastric nesfatin-1/ NUCB2. Cell Physiol Biochem 29:493-500.

Mimee A, Smith PM, Ferguson AV (2012) Nesfatin-1 influences the excitability of neurons in the nucleus of the solitary tract and regulates cardiovascular function. Am J Physiol Regul Integr Comp Physiol 302:1297-1304.

Miura K, Titani K, Kurosawa Y, Kanai Y (1992) Molecular cloning of nucleobindin, a novel DNA-binding protein 
that contains both a signal peptide and a leucine zipper structure. Biochem Biophys Res Commun 187: 375-380.

Mohan H, Unniappan S (2012) Ontogenic pattern of nucleobindin-2/nesfatin-1 expression in the gastroenteropancreatic tissues and serum of Sprague Dawley rats. Regul Pept 175:61-69.

Oh-I S, Shimizu H, Satoh T, Okada S, Adachi S, Inoue K, Eguchi H, Yamamoto M, Imaki T, Hashimoto K, Tsuchiya T, Monden T, Horiguchi K, Yamada M, Mori M (2006) Identification of nesfatin-1 as a satiety molecule in the hypothalamus. Nature 443:709-712.

Osaki A, Shimizu H, Ishizuka N, Suzuki Y, Mori M, Inoue S (2012). Enhanced expression of nesfatin/ nucleobindin-2 in white adipose tissue of ventromedial hypothalamus-lesioned rats. Neurosci Lett 521:46-51. Ramanjaneya M, Chen J, Brown JE, Tripathi G, Hallschmid M, Patel S, Kern W, Hillhouse EW, Lehnert H, Tan BK, Randeva HS (2010) Identification of nesfatin-1 in human and murine adipose tissue: a novel depotspecific adipokine with increased levels in obesity. Endocrinology 151:3169-3180.

Stengel A, Goebel M, Wang L, Kato I, Mori M, Taché Y (2012) Nesfatin-130-59 but not the N- and Cterminal fragments, nesfatin-11-29 and nesfatin-160-82 injected intracerebroventricularly decreases dark phase food intake by increasing inter-meal intervals in mice.
Peptides 35:143-148.

Stengel A, Goebel M, Wang L, Rivier J, Kobelt P, Mönnikes H, Lambrecht NW, Taché Y (2009a) Central nesfatin-1 reduces darkphase food intake and gastric emptying in rats: differential role of corticotropinreleasing factor 2 receptor. Endocrinology 150:49114919.

Stengel A, Goebel M, Wang L, Taché Y (2009b) Ghrelin, des-acyl ghrelin and nesfatin-1 in gastric X/A-like cells: role as regulators of food intake and body weight. Peptides 31:357-369.

Stengel A, Goebel M, Yakubov I, Wang L, Witcher D, Coskun T, Taché Y, Sachs G, Lambrecht NW (2009c) Identification and characterization of nesfatin-1 immunoreactivity in endocrine cell types of the rat gastric oxyntic mucosa. Endocrinology 150:232-238.

Stengel A, Taché Y (2010) Nesfatin-1 - Role as possible new potent regulator of food intake. Regl Pept 163: 18-23.

Yosten GL, Samson WK (2009) Nesfatin-1 exerts cardiovascular actions in brain: possible interaction with the central melanocortin system. Am J Physiol Regul Integr Comp Physiol 297:330-336.

Zhang AQ, Li XL, Jiang CY, Lin L, Shi RH, Chen JD, Oomura Y (2010) Expression of nesfatin-1/NUCB2 in rodent digestive system. World J Gastroenterol 16: 1735-1741. 